\title{
Sudden cardiac arrest during Nuss procedure for pectus excavatum
}

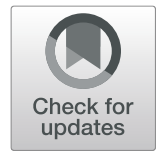

\author{
Do Yeon Kim and Jin Yong Jeong ${ }^{*}$ (D)
}

\begin{abstract}
Cardiac arrest during the Nuss procedure is the most serious complication and is related to cardiac injury by the surgical instruments and pectus bars. To avoid the cardiac injury, there are several techniques with various devices, including crane and wire suture, lifting hook, the Kent or Langenbeck retractor, and the Vacuum Bell device. However, a case of cardiac arrest without direct cardiac injury during the Nuss procedure has been reported in the pectus excavatum patient with coronary-to-pulmonary arterial shunts. Recently, we encountered a case of cardiac arrest without cardiac abnormalities in preoperative studies and cardiac injury during the Nuss procedure.
\end{abstract}

Keywords: Pectus excavatum, Nuss procedure, Complications, Cardiac arrest

\section{Correspondence.}

\section{Dear Sir,}

We read with great interest the report by Zou et al. presenting the case of cardiac arrest without physical cardiac injury during the Nuss procedure [1]. A lifethreatening complication during the Nuss procedure is cardiac injury by the surgical instruments and pectus bars, which may result in cardiac arrest [2,3]. Zou et al. encountered cardiac arrest twice during a modified Nuss procedure, when pulling the pectus bar and after rotating the bar, in the patient with pectus excavatum. The patient's preoperative echocardiography showed two abnormal transverse shunts classified as coronary-topulmonary arterial shunts. Recently, we also encountered a case of sudden cardiac arrest without cardiac injury during the Nuss procedure in the pectus excavatum patient, whose preoperative electrocardiogram and echocardiogram showed no abnormality.

A 17-year-old male presented with depressed chest deformity since childhood without special medical history. Chest computed tomography scans revealed symmetrical

\footnotetext{
* Correspondence: jeong74@catholic.ac.kr

Department of Thoracic and Cardiovascular Surgery, Incheon St. Mary's Hospital, College of Medicine, The Catholic University of Korea, 56 Dongsu-ro, Bupyeong-gu, Incheon 21431, Republic of Korea
}

depression of the lower anterior chest wall with indentation on the heart and a Haller index of 4.0 (Fig. 1a). Preoperative electrocardiography showed sinus rhythm with right atrium enlargement and borderline right axis deviation. Preoperative echocardiography demonstrated normal cardiac chamber dimensions and normal left and right ventricular contractility. The patient underwent the Nuss procedure in supine position. When dissecting the substernal space after applying the crane technique to lift the sternum to avoid cardiac injury [4], ventricular fibrillation occurred suddenly after the appearance of bradycardia and premature ventricular contractions (Fig. 1b). Sinus rhythm was restored after immediate cardiopulmonary resuscitation including chest compressions and administrations of an electric cardioversion and anti-arrhythmic agents (Fig. 1c). The operation was terminated and the patient was transferred to the intensive care unit. A cardiologist recommended further evaluations but the patient refused the recommendation and was discharged with good recovery 4 days later. The patient visited our hospital for 3 years without surgical complications.

Cardiac arrest during the Nuss procedure is mostly related to cardiac injury such as cardiac perforation and physical stimulation to the heart with a surgical instrument and oppression of the right ventricular outflow. 


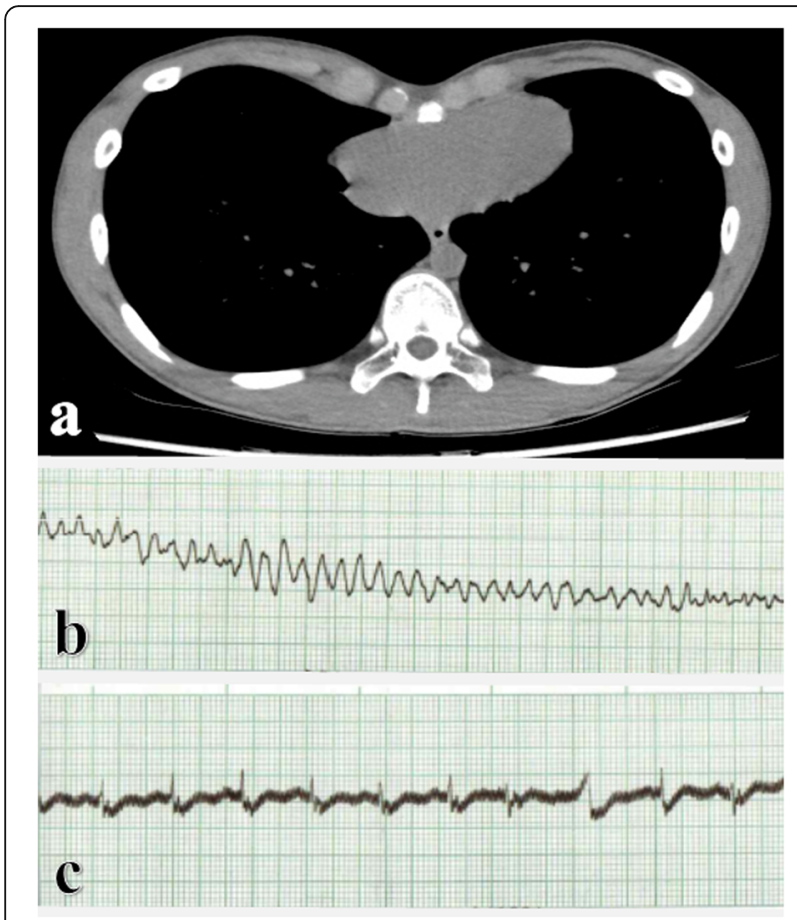

Fig. 1 a The preoperative chest computed tomography scans showing symmetrical depression of the anterior chest wall and cardiac indentation. b Electrocardiographic monitoring in the operating room revealing ventricular fibrillation during the Nuss procedure and c Sinus rhythm restoring after immediate cardiopulmonary resuscitation

Several techniques have been used to avoid cardiac injury during the Nuss procedure [4-6]. Lifting the sternum is the key to releasing the substernal space in which the pectus bar will be inserted and placed. Various devices, including crane and wire suture, lifting hook, the Kent or Langenbeck retractor, and the Vacuum Bell device, have been used to lift the sternum.

Cardiac arrest not related to cardiac injury during the Nuss procedure rarely occurs. Zou et al. hypothesized two possible mechanisms in their case [1]. First, rotation of the heart by sternal elevation twisted the coronary-topulmonary arterial shunts, resulting in directional change of blood flow in the shunts, caused acute myocardial ischemia and consequent ventricular fibrillation. Second, nerve stretching caused by sudden enlargement of the substernal space may upset the balance between vagal and sympathetic innervation, which triggers inhibition of cardiac function and consequent arrest. In our case, preoperative eletrocardiography and echocardiography revealed no abnormal findings and we thought that cardiac arrest of our case may be related to nerve stretching caused by sternal elevation.

In summary, we encountered a case of cardiac arrest without cardiac injury during the Nuss procedure in the pectus excavatum patient with normal electrocardiogram and echocardiogram. We would like to emphasize that cardiac arrest may occur due to sternal elevation even if there is no abnormality in the preoperative cardiac examination and no cardiac injury during the Nuss procedure.

\section{Acknowledgements}

Not applicable.

\section{Authors' contributions}

DYK: Study design, data collection and manuscript writing. JYJ: Study design, data collection and manuscript writing. All authors read and approved the final manuscript.

\section{Funding}

There is no funding for the work.

Availability of data and materials Not applicable.

Ethics approval and consent to participate

Ethics approval was received by the institutional ethics committee.

\section{Consent for publication}

Written informed consent was obtained from all patients or their parents for the publication of this report and any accompanying images.

\section{Competing interests}

The authors declare that they have no competing interests.

Received: 6 October 2019 Accepted: 2 June 2020

Published online: 12 June 2020

References

1. Zou J, Luo C, Liu Z, Cheng C. Cardiac arrest without physical cardiac injury during Nuss repair of pectus excavatum. J Cardiothorac Surg. 2017;12:61.

2. Schaarschmidt K, Lempe M, Schlesinger F, Jaeschke U, Park W, Polleichtner S. Lessons learned from lethal cardiac injury by nuss repair of pectus excavatum in a 16-year-old. Ann Thorac Surg. 2013;95:1793-5.

3. Bouchard S, Hong AR, Gilchrist BF, Kuenzler KA. Catastrophic cardiac injuries encountered during the minimally invasive repair of pectus excavatum. Semin Pediatr Surg. 2009;18:66-72.

4. Park HJ, Jeong JY, Jo WM, Shin JS, Lee IS, Kim KT, Choi YH. Minimally invasive repair of pectus excavatum: a novel morphology-tailored, patientspecific approach. J Thorac Cardiovasc Surg. 2010;139:379-86.

5. Takahashi T, Okazaki T, Yamataka A, Uchida E. Usefulness of Kent retractor and lifting hook for Nuss procedure. Pediatr Surg Int. 2015;31: $1103-5$.

6. Togoro SY, Tedde ML, Eisinger RS, Okumura EM, de Campos JRM, PêgoFernandes PM. The Vacuum Bell device as a sternal lifter: An immediate effect even with a short time use. J Pediatr Surg. 2018;53:406-10.

\section{Publisher's Note}

Springer Nature remains neutral with regard to jurisdictional claims in published maps and institutional affiliations.
Ready to submit your research? Choose BMC and benefit from:
- fast, convenient online submission
- thorough peer review by experienced researchers in your field
- rapid publication on acceptance
- support for research data, including large and complex data types
- gold Open Access which fosters wider collaboration and increased citations
- maximum visibility for your research: over $100 \mathrm{M}$ website views per year
At $\mathrm{BMC}$, research is always in progress.
Learn more biomedcentral.com/submissions 